\title{
Neurocognitive mechanisms of fear conditioning and vulnerability to anxiety
}

\author{
Joseph E. Dunsmoor, Fredrik Åhs and Kevin S. LaBar* \\ Department of Psychology and Neuroscience, Center for Cognitive Neuroscience, Duke University, Durham, NC, USA \\ *Correspondence: klabar@duke.edu
}

\section{A commentary on}

Fear-conditioning mechanisms associated with trait vulnerability to anxiety in humans

by Indovina, I., Robbins, T. W., NúñezElizalde, A. O., Dunn, B. D., and Bishop, S. J. (2011). Neuron 69, 563-571.

Although anxiety disorders are the most common of psychiatric diseases with $28 \%$ life prevalence (Kessler et al., 2005), the etiology and neurobehavioral mechanisms underlying anxiety are not fully understood. Anxiety has commonly been separated into dimensions of state and trait anxiety (Freud, 1924; Spielberger, 1966). State anxiety constitutes the transitory negative emotions elicited by a stressor whereas trait anxiety refers to the predisposition to react negatively to stressful situations. Twin studies suggest both genetic and environmental contributions to trait anxiety (Lau et al., 2006). In addition, investigations have begun to demonstrate the role of genetic factors in fear conditioning in humans (Hettema et al., 2003; Lonsdorf et al., 2009), suggesting that genetic influences might determine how we learn from stressful experiences. The idea that fear conditioning provides an explanation for the acquisition of anxiety disorders has a long and storied history in psychological science (e.g., Pavlov, 1927; Mineka and Zinbarg, 2006). In the classic view, the evolutionarily adaptive capacity to defensively respond to learned threats can lead to maladaptive behavior. For instance, an anxious individual may learn that a stimulus or situation is threatening, which may then lead to pathological reactions (e.g., phobias and post-traumatic stress disorder). Understanding how humans control learned fear can provide more effective clinical treatments and has spurred numerous investigations into the brain mechanisms underlying fear regulation.

Illuminated by previous investigations on frontal-limbic involvement in fear regulation, a recent fMRI study in Neuron by
Indovina et al. (2011) examined individual differences in trait anxiety on cued and contextual fear conditioning in psychologically healthy adults. The authors hypothesized that trait anxiety influences brain activity in response to learned threat, with implications toward understanding the neurocognitive mechanisms underlying resilience to anxiety. During fMRI scanning, participants viewed images of three different rooms containing an actor (conditioned stimulus, CS). In one room, the CS signaled the delivery of a 103-dB aversive scream (unconditioned stimulus, US) by raising his hands to his ears. In another room, the US was not signaled by the CS. A third room contained no US presentations and was thus considered safe. The authors made predictions concerning two brain regions: the amygdala and the ventral prefrontal cortex (vPFC).

The brain imaging results revealed a separation in cued versus contextual fear responses. The CS presented in the predictable room evoked phasic amygdala responses that correlated with trait anxiety levels; subjects with high trait anxiety showed stronger amygdala responses to the CS in the predictable room versus the CS in the safe room. However, this finding is somewhat difficult to interpret because the authors did not include an explicitly unpaired or randomly paired control stimulus (i.e., CS-) within the different contexts, as is the standard methodology in neuroimaging studies of fear conditioning (Buchel and Dolan, 2000) ${ }^{1}$. Since the authors did not control for non-associative phasic responses (e.g., sensitization) within the three contexts, it is not clear whether activity to the CS in the different rooms is a consequence of stronger acquisition per se, or heightened reactivity in general (Lissek et al., 2005). The relationship between trait anxiety and amygdala activity has previously been demonstrated during extinction in healthy adults, such that sustained amygdala responses during extinction are correlated with trait anxiety scores (Barrett and Armony, 2009; Sehlmeyer et al., 2010). However, these investigations did not find an association between amygdala activation and trait anxiety during fear acquisition. This raises a concern that the amygdala findings of Indovina et al. (2011) may not replicate when non-associative control procedures are in place.

In contrast to the results for the amygdala, Indovina et al. (2011) found that the predictive CS evoked increased phasic activity in the vPFC that was inversely related with trait anxiety; subjects with low trait anxiety showed stronger vPFC activity to the CS in the predictable room versus the unpredictable room. Low trait anxious subjects also showed greater sustained vPFC activity throughout the fear-related unpredictable context relative to high trait anxious individuals. The authors concluded that activation in the vPFC demonstrates a role for this region in the automatic regulation of fear prior to fear extinction. As increased vPFC activity was observed primarily in low trait anxious individuals and was inversely correlated with SCRs, this region may provide a marker of resilience to anxiety disorders. While this is a

${ }^{1}$ Indovina et al. (2011) only report difference scores in amygdala activity, which leaves out important information regarding the magnitude of brain responses to the CS in the predictable and safe room. For instance, it is not possible to determine from difference scores if high and low trait anxious individuals showed similarly strong amygdala responses to the aversive CS in the predictable room, but only high trait-anxious individuals expressed lower amygdala responses to the CS in the safe room. It appears that there is little difference in amygdala activity to the CS in the predictable and safe rooms among low anxious subjects - only high trait anxious subjects show a differential response. A lack of differential amygdala activity to the CS in the predictable and unpredictable room among the low trait anxious subjects could indicate a lack of specificity (if amygdala activity is high in both contexts) or an overall lack of reactivity (if amygdala activity is low in both contexts). Reporting separate estimates of brain activity across all conditions would help to resolve this issue. 
potentially exciting possibility, it would also be important to know whether engagement of this region across subjects or trials results in down-regulation of amygdala fear signals or self-reported regulation attempts.

The vPFC region of interest (ROI) is not an area commonly implicated in the inhibition of conditioned fear. As noted by Indovina et al. (2011), hypotheses regarding the role of the vPFC in their study were in contrast to the classic view held in the rodent and human fear conditioning literature, which regards the medial PFC as primarily involved in reducing fear responses through interconnections with the amygdala and hippocampus during extinction learning and recall of extinction memories (Milad and Quirk, 2002; Ehrlich et al., 2009).The vPFC ROI was defined on the basis of a prior investigation of placeboinduced brain activity during anticipation of pain, where it was described as the orbitofrontal cortex (OFC; Wager et al., 2004). The description of this area as "vPFC" throughout Indovina et al. (2011) is vague (activation appears to encompass portions of the vmPFC, vlPFC, and OFC), so it will be important to delineate the relative contribution of this area with other PFC regions involved in aspects of emotion regulation. The vPFC region appears to bridge two areas that have been implicated in prior studies of emotion regulation: a lateral PFC region involved in voluntary regulation attempts and a medial PFC region involved in outcome-based/non-instructed forms of regulation (Ochsner and Gross, 2008; Etkin et al., 2011).For instance, the anterior ventrolateral PFC - a region close to the vPFC region of Indovina et al. (2011) has been implicated in voluntary cognitive reappraisal via down-regulation of amygdala responses (Winecoff et al., 2010) and subsequent memory for reappraised emotional stimuli via hippocampal interactions (Hayes et al., 2010). Moreover, Delgado et al. (2008) showed a link between the dorsolateral PFC and vmPFC during instructed down-regulation of conditioned fear. Since Indovina et al. (2011) did not report a whole-brain analysis, it will be important in future studies to determine the unique contribution of this $\mathrm{VPFC}$ region relative to these other areas.

Finally, it is important to consider the possible alternatives to the adaptive role of this vPFC signal. The authors interpret
vPFC activity as a marker of automatic fear regulation. Yet, this activity occurs prior to extinction and it is therefore appropriate to regard the predictable cue and unpredictable context as fear-relevant. To be characteristic of maladaptive responding, activity should be assessed during generalization testing (Dunsmoor et al., 2011), reversal (Schiller et al., 2008), or extinction learning/recall, as demonstrated by Milad et al. (2009) for individuals with PTSD relative to trauma-exposed control subjects. Indovina et al. (2011) appear to make the argument that the automatic regulation of fear is adaptive even in situations in which the US is still expected. In fact, with the threat of the US still present, an over-regulation of fear responses can be detrimental to low-anxious participants if they are not prepared to defensively respond to the US when it inevitably occurs (Domjan, 2005). Thus, the vPFC signal may in fact be maladaptive to low-anxious individuals. Still another alternative interpretation is that the $\mathrm{PFC}$ signal relates to the predictive value of features in the environment that signal the US. In the predictable room, the CS was the most reliable predictor of the US whereas in the unpredictable room, the context itself was the most reliable predictor. Notably, across these two conditions, low-anxious participants engaged the vPFC region. Rather than reflecting emotion regulation, the vPFC may signal a more abstract representation of motivational value and/or salience in lowanxious participants, consistent with models of this region in reinforcement learning (Rolls, 1996; Rangel et al., 2008). According to this view, the lack of vPFC activation in the high-anxious individuals may be maladaptive but for a different reason.

While the results from Indovina et al. (2011) provide potentially novel insights into the relationship between psychological factors and fear conditioning, it will be important to determine whether the findings extend to individuals with clinical anxiety disorders. Further research is needed to address whether a vulnerability to develop an anxiety disorder in high trait-anxious individuals is characterized by enhanced conditionability to cue (Orr et al., 2000) or context (Grillon, 2002), overgeneralization of fear to safety cues (Grillon and Morgan, 1999), deficits in extinction recall (Milad et al., 2009), or some combination thereof (see Lissek et al., 2005). Another intriguing question that remains to be answered is whether the same genetic factors that contribute to individual differences in fear conditioning also contribute to trait anxiety, and whether the putative brain functions delineated by Indovina et al. (2011) could serve as an intermediate phenotype for these factors.

\section{REFERENCES}

Barrett, J., and Armony, J. L. (2009). Influence of trait anxiety on brain activity during the acquisition and extinction of aversive conditioning. Psychol. Med.39, 255-265.

Buchel, C., and Dolan, R. J. (2000). Classical fear conditioning in functional neuroimaging. Curr. Opin. Neurobiol. 10, 219-223.

Delgado, M. R., Nearing, K. I., LeDoux, J. E., and Phelps, E. A. (2008). Neural circuitry underlying the regulation of conditioned fear and its relation to extinction. Neuron 59, 829-838.

Domjan, M. (2005). Pavlovian conditioning: a functional perspective. Annu. Rev. Psychol. 56, 179-206.

Dunsmoor, J. E., Prince, S. E., Murty, V. P., Kragel, P. A., and LaBar, K. S. (2011). Neurobehavioral mechanisms of human fear generalization. Neuroimage 55, 1878-1888.

Ehrlich, I., Humeau, Y., Grenier, F., Ciocchi, S., Herry, C., and Luthi, A. (2009). Amygdala inhibitory ircuits and the control of fear memory. Neuron 62, 757-771.

Etkin, A., Egner, T., and Kalisch, R. (2011). Emotional processing in anterior cingulate and medial prefrontal cortex. Trends Cogn. Sci. 15, 85-93.

Freud, S. (1924). Collected Papers, Vol. 1.London: Hogarth Press.

Grillon, C. (2002). Startle reactivity and anxiety disorders: aversive conditioning, context, and neurobiology. Biol. Psychiatry 52, 958-975.

Grillon, C., and Morgan, C. A. (1999). Fear-potentiated startle conditioning to explicit and contextual cues in gulf war veterans with posttraumatic stress disorder J. Abnorm. Psychol. 108, 134-142.

Hayes, J. P., Morey, R. A., Petty, C. M., Seth, S., Smoski, M. J., McCarthy, G., and LaBar, K. S. (2010). Staying cool when things get hot: emotion regulation modulates neural mechanisms of memory encoding. Front. Hum. Neurosci. 4:230. doi: 10.3389/fnhum.2010.00230

Hettema, J. M., Annas, P., Neale, M. C., Kendler, K. S., and Fredrikson, M. (2003). A twin study of the genetics of fear conditioning. Arch. Gen. Psychiatry 60, 702-708. Indovina, I., Robbins, T.W., Núñez-Elizalde,A. O., Dunn, B. D., and Bishop, S. J. (2011). Fear-conditioning mechanisms associated with trait vulnerability to anxiety in humans. Neuron 69, 563-571.

Kessler, R. C., Berglund, P., Demler, O., Jin, R., and Walters, E. E. (2005). Lifetime prevalence and age-of-onset distributions' of DSM-IV disorders in the national comorbidity survey replication. Arch. Gen. Psychiatry 62, 593-602.

Lau, J. Y. F., Eley, T. C., and Stevenson, J. (2006). Examining the state-trait anxiety relationship: a behavioural genetic approach. J. Abnorm. Child. Psychol. 34, 19-27.

Lissek, S., Powers, A. S., Mcclure, E. B., Phelps, E. A., Woldehawariat, G., Grillon, C., and Pine, D. S. (2005). Classical fear conditioning in the anxiety disorders: a meta-analysis. Behav. Res. Ther. 43, 1391-1424. 
Lonsdorf, T. B., Weike, A. I., Nikamo, P., Schalling, M., Hamm, A. O., and Öhman, A. (2009). Genetic gating of human fear learning and extinction: possible implications for gene-environment interaction in anxiety disorder. Psychol. Sci. 20, 198-206.

Milad, M. R., Pitman, R. K., Ellis, C. B., Gold, A. L., Shin, L. M., Lasko, N. B., Zeidan, M. A., Handwerger, K., Orr, S. P., and Rauch, S. L. (2009). Neurobiological basis of failure to recall extinction memory in posttraumatic stress disorder. Biol. Psychiatry 66, 1075-1082.

Milad, M. R., and Quirk, G. J. (2002). Neurons in medial prefrontal cortex signal memory for fear extinction. Nature 420, 70-74.

Mineka, S., and Zinbarg, R. (2006). A contemporary learning theory perspective on the etiology of anxiety disorders - It's not what you thought it was. Am. Psychol. 61, 10-26.

Ochsner, K. N., and Gross, J. J. (2008). Cognitive emotion regulation: insights from social cognitive and affective neuroscience. Curr. Dir. Psychol. Sci. 17, 153-158.

Orr, S. P., Metzger, L. J., Lasko, N. B., Macklin, M. L., Peri, T., and Pitman, R. K. (2000). De novo conditioning in trauma-exposed individuals with and without posttraumatic stress disorder. J. Abnorm. Psychol. 109, 290-298.

Pavlov, I. P. (1927). Conditioned Reflexes. London: Oxford University Press.

Rangel, A., Camerer, C., and Montague, P. R. (2008). A framework for studying the neurobiology of value-based decision making. Nat. Rev. Neurosci. 9, $545-556$.

Rolls, E. T. (1996). The orbitofrontal cortex. Philos. Trans. R. Soc. Lond. B Biol. Sci. 351, 1433-1443 [Discussion 1443-1434].

Schiller, D., Levy, I., Niv, Y., LeDoux, J. E., and Phelps, E. A. (2008). From fear to safety and back: reversal of fear in the human brain. J. Neurosci. 28, 11517-11525.

Sehlmeyer, C., Dannlowski, U., Schoning, S., Kugel, H., Pyka, M., Pfleiderer, B., Zwitserlood, P., Schiffbauer, H., Heindel, W., Arolt, V., and Konrad, C. (2010). Neural correlates of trait anxiety in fear extinction. Psychol. Med. 41, 1-10.

Spielberger, C. D. (1966). Anxiety and Behaviour. New York: Academic Press.
Wager, T. D., Rilling, J. K., Smith, E. E., Sokolik, A., Casey, K. L., Davidson, R. J., Kosslyn, S. M., Rose, R. M., and Cohen, J. D. (2004). Placebo-induced changes in FMRI in the anticipation and experience of pain. Science 303, 1162-1167.

Winecoff, A., LaBar, K. S., Madden, D. J., Cabeza, R., and Huettel, S. A. (2010). Cognitive and neural contributors to emotion regulation in aging. Soc. Cogn. Affect. Neurosci. doi: 10.1093/scan/nsq030. [Epub ahead of print].

Received: 17 March 2011; accepted: 21 March 2011; published online: 04 April 2011.

Citation: Dunsmoor JE, Âs F and LaBar KS (2011) Neurocognitive mechanisms of fear conditioning and vulnerability to anxiety. Front. Hum. Neurosci. 5:35. doi: 10.3389/fnhum.2011.00035

Copyright (c) 2011 Dunsmoor, Ahs and LaBar. This is an open-access article subject to a non-exclusive license between the authors and Frontiers Media SA, which permits use, distribution and reproduction in other forums, provided the original authors and source are credited and other Frontiers conditions are complied with. 